\title{
Analysis of the effect of formation potential on the electrochemical response of doped titanium oxides
}

Steven A. Policastro ${ }^{*}$, Rachel M. Anderson, Donald F. Roeper, and Derek J. Horton

\begin{abstract}
The electrochemical and semiconductor behavior of oxides of pure Ti and two Ti-based binary alloys, $\mathrm{Ti}_{99} \mathrm{Sn}_{1}$ and $\mathrm{Ti}_{99} \mathrm{Cr}_{1}$, were investigated using electrochemical impedance spectroscopy (EIS), Mott-Schottky analysis, intensity modulated photocurrent spectroscopy (IMPS), and potentiodynamic polarization in order to understand differences in measured oxygen reduction catalytic activity with the goal of suppressing the capability of titanium to drive galvanic corrosion. The combination of EIS techniques with IMPS was used to determine such semiconductor properties as the band gaps, flat band potentials, dielectric constants, defect concentrations, and catalytic properties, i.e., the reaction rate constants, of the oxides. The semiconductor properties of the oxides were observed to change as a function of oxide formation potential but the greatest changes in oxygen reduction rates in an alkaline solution were only found to occur with alloying, with the greatest decrease seen for the $\mathrm{Ti}_{99} \mathrm{Sn}_{1}$ alloy.
\end{abstract}

\section{Keywords}

Titanium oxide; oxygen reduction reaction; intensity modulated photocurrent spectroscopy; galvanic corrosion 


\section{1. Introduction}

34 In galvanic corrosion, unlike in other forms of corrosion, the electrochemical properties of the 35 cathodic material are almost as important as the properties of the anodic material in determining 36 the rate of corrosion. While the potential difference between the two materials gives an 37 indication of the thermodynamic driving force for galvanic corrosion, it is, of course, the 38 magnitude of the corrosion current that determines the amount of anode dissolution [1]. The sites 39 for metal oxidation and oxygen reduction are located on the different materials of the galvanic 40 couple; thereby requiring the establishment of an electron transport path between the materials of 41 the galvanic couple. The corrosion rate of the more active material in the galvanic couple is 42 strongly influenced by such environmental conditions as the presence of aggressive anions, 43 which impact anodic reaction kinetics, but also, in many instances, by the amount of exposed 44 surface area of the cathode and by the ability of the cathode to support a suitable reduction 45 reaction [2-4]. Of particular interest to this work is the oxygen reduction reaction (ORR), with 46 the overall reaction given in equation (1)[5].

$$
\mathrm{O}_{2}+2 \mathrm{H}_{2} \mathrm{O}+4 e^{-} \leftrightarrow 4 \mathrm{OH}^{-}
$$

48 The ORR on transition metal oxides, as on platinum, can proceed via either the 2-electron or 449 electron pathway. However, unlike platinum, the surface cations of a transition metal oxide do 50 not have their full complement of oxygen anions and so they coordinate with the oxygen atoms 51 in water molecules that become adsorbed onto the oxide surface [6]. To create $\mathrm{OH}^{-}$ions, the 52 reduction of the surface metal cation must compensate the protonation of the surface oxygen

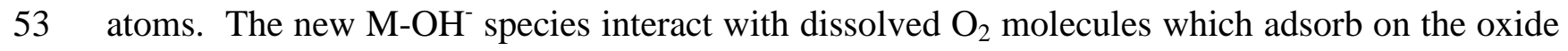
54 surface in either the end-on or side-on configurations. The direct pathway on $\mathrm{TiO}_{2}$ in alkaline 55 solutions is suggested to proceed in the following manner [7]:

$$
\begin{aligned}
\mathrm{Ti}^{4+}-\mathrm{O}^{2-}+\mathrm{H}_{2} \mathrm{O}+\mathrm{e}^{-} \rightarrow \mathrm{Ti}^{3+}-\mathrm{OH}^{-}+\mathrm{OH}^{-} \\
\mathrm{O}_{2}+\mathrm{e}^{-} \rightarrow \mathrm{O}_{2, a d s}^{-} \\
\mathrm{Ti}^{3+}-\mathrm{OH}^{-}+\mathrm{O}_{2, a d s}^{-} \rightarrow \mathrm{Ti}^{4+}-\mathrm{O}-\mathrm{O}^{2-}+\mathrm{OH}^{-}
\end{aligned}
$$




$$
\begin{gathered}
\mathrm{Ti}^{4+}-\mathrm{O}-\mathrm{O}^{2-}+\mathrm{H}_{2} \mathrm{O}+\mathrm{e}^{-} \rightarrow \mathrm{Ti}^{3+}-\mathrm{O}-\mathrm{OH}^{-}+\mathrm{OH}^{-} \\
\mathrm{Ti}^{3+}-\mathrm{O}-\mathrm{OH}^{-}+\mathrm{e}^{-} \rightarrow \mathrm{Ti}^{4+}-\mathrm{O}^{2-}+\mathrm{OH}^{-}
\end{gathered}
$$

57 where $\mathrm{Ti}^{3+}-\mathrm{OH}^{-}$, for example, indicates a coordination complex. Competition from the indirect 58 pathway can replace equation (5):

$$
\mathrm{Ti}^{4+}-\mathrm{O}-\mathrm{O}^{2-}+\mathrm{H}_{2} \mathrm{O}+\mathrm{e}^{-} \rightarrow \mathrm{Ti}^{3+}+\mathrm{OH}^{-}+\mathrm{HO}^{2-}
$$

60 The reaction in equation (5) is thought to be the rate-determining step (RDS) for the direct 61 pathway and the step in equation (7) is considered the RDS for the indirect pathway.

62 The ORR rate on $\mathrm{TiO}_{2}$ can be expressed using a Butler-Volmer formulation[6]:

$$
j=j_{0}\left(1-\theta_{B}\right) e^{\left[-\frac{\alpha F\left(E-E_{0}\right)}{R T}\right]} e^{\left[-\frac{\alpha \Delta G_{B}^{0}}{R T}\right]}
$$

64 where $\mathrm{j}_{0}$ is the exchange current density, $\theta_{\mathrm{B}}$ is the surface coverage of $\mathrm{OOH}^{-}$provided by a 65 Langmuir adsorption isotherm, $\mathrm{E}$ is the constant potential, $\mathrm{E}_{0}$ is the standard state reversible 66 potential, $\alpha$ is the charge transfer coefficient, and $\Delta \mathrm{G}_{\mathrm{B}}{ }^{0}$ is the free energy difference between 67 adsorbed and non-adsorbed $\mathrm{OOH}^{-}$from equation (5). Then, for a constant potential, the reaction 68 rate:

73 These opposing influences give rise to a "volcano" curve when plotting reaction rate versus 74 adsorption energy.

75 Computer simulations of oxygen reduction reactions on various transition metal oxides that 76 predicted ORR "volcano" curves[8], suggested that tin and chromium would be potentially 77 disruptive elements to consider as alloying elements in titanium. Electrochemical measurements 78 of natively formed oxides on titanium with these alloying elements, in prior work [9], indicated 
79 that ORR kinetics could be decreased. These prior results suggested that, in order to investigate 80 the underlying mechanisms, the following courses of action needed to be pursued:

81 (1) Use available electrochemical measurement techniques to confirm the effect of alloying on the reaction shown in equations (2) - (6).

83 (2) Evolve the native oxides under potentiostatic control to determine if oxide thickness $84 \quad$ and/or composition could impact catalysis 


\section{Experimental Details}

\subsection{Alloy formation}

Titanium (99.995\% purity) and Ti-based minor solute alloy ingots were produced at solute concentration of 1 at\% using the arc-melting technique using high purity metals (Sn 99.999\% and $\mathrm{Cr}$ 99.996\%). Ingots were suction cast into a custom copper mold consisting of two cylindrical regions of $1 \mathrm{~cm}$ and $0.6 \mathrm{~cm}$ diameter, the latter for RDE test specimens, which were then annealed for four hours at $827^{\circ} \mathrm{C}$, within the single phase HCP region, followed by a water quench. The casts were then machined and ground to $4 \mathrm{~mm}$ diameter discs. X-ray diffraction (XRD), using $\mathrm{Cu}$ k- $\alpha$ X-rays, was used to verify single phase structure and determine the lattice coefficients using whole pattern fits. Prior to electrochemical testing, samples were abraded using successively finer grits to 1200 grit $\mathrm{SiC}$ paper, then polished using 1 micron alumina. For baseline electrochemical testing, samples were mounted in insulating epoxy.

\subsection{Chemical property characterization}

X-ray photoelectron spectroscopy (XPS) scans were performed on each of the oxides to determine oxide composition using a k- $\alpha$ XPS system. An Al k- $\alpha$ x-ray source was used for monochromatic radiation that was focused to a $400 \mu \mathrm{m}$ diameter spot size. Twenty highresolution scans of the pure $\mathrm{Ti}$ were examined to provide baseline oxide information on the native $\mathrm{Ti}$ oxide while 50 high-resolution scans of each alloying element were performed to maximize signal capture to aid in determining values of the dopant concentrations. Data analysis was performed using the CasaXPS software system.

\subsection{Semiconductor property characterization}

Electrochemical impedance spectroscopy (EIS) characterization of the various titanium alloys was performed in $0.6 \mathrm{M} \mathrm{NaCl}+0.01 \mathrm{M} \mathrm{NaOH}(\mathrm{pH}$ 12) solution using a platinum wire counter electrode and a saturated calomel (SCE) reference electrode. The titanium alloy oxides were stabilized at room temperature and ambient aeration for 1 hour. The EIS scans were performed at the oxides' open-circuit potentials with a $5 \mathrm{mV}_{\mathrm{RMS}}$ perturbation at frequencies from $100 \mathrm{kHz}$ to $0.1 \mathrm{~Hz}$.

Mott-Schottky (MS) analysis of the various oxides was performed in $0.6 \mathrm{M} \mathrm{NaCl}+0.01 \mathrm{M}$ $\mathrm{NaOH}$ ( $\mathrm{pH}$ 12) solution using a platinum wire counter electrode and a saturated calomel 
reference electrode. The titanium alloy oxides were stabilized at room temperature and ambient aeration for 1 hour. The applied DC potentials were stepped in $100 \mathrm{mV}$ increments from $-0.3 \mathrm{~V}$ vs. SCE to $-1.9 \mathrm{~V}$ vs. SCE. The oscillating potential was applied at $100 \mathrm{~Hz}$ at $\pm 5 \mathrm{mV}_{\mathrm{RMS}}$.

137 potentials were stepped at a rate of $-0.167 \mathrm{mV} / \mathrm{sec}$.

\subsection{Photoelectrochemical property characterization}

Intensity modulated photocurrent spectroscopy (IMPS) characterization[10] of the various oxides was also performed in $0.6 \mathrm{M} \mathrm{NaCl}+0.01 \mathrm{M} \mathrm{NaOH}(\mathrm{pH}$ 12) solution using a platinum wire counter electrode and a silver-oxide pseudo-reference cell[11]. The titanium alloy oxides were stabilized at room temperature and ambient aeration for 1 hour. Two potentiostats were used for these characterizations. The primary potentiostat applied the baseline DC current and AC modulation to the LED while the secondary potentiostat received the clock signal from the primary potentiostat and measured the response of the sample. The AC current supplied to the LED varied in frequency from $5000 \mathrm{~Hz}$ to $0.1 \mathrm{~Hz}$ while the magnitude of the oscillation was varied to account for the maximum current permitted through the LED. Fifteen LEDs were used that spanned the spectrum from infrared to ultraviolet light: $1450 \mathrm{~nm}, 1200 \mathrm{~nm}, 850 \mathrm{~nm}, 660 \mathrm{~nm}$, $617 \mathrm{~nm}, 590 \mathrm{~nm}, 530 \mathrm{~nm}, 505 \mathrm{~nm}, 470 \mathrm{~nm}, 420 \mathrm{~nm}, 405 \mathrm{~nm}, 385 \mathrm{~nm}, 375$, nm, $365 \mathrm{~nm}$, and 310 $\mathrm{nm}$, identified by the emitted wavelength with the highest intensity.

\subsection{Electrochemical property characterization}

Potentiodynamic polarization characterization of the various titanium alloys was performed in $0.6 \mathrm{M} \mathrm{NaCl}+0.01 \mathrm{M} \mathrm{NaOH}(\mathrm{pH} \mathrm{12})$ electrolyte with a platinum wire counter electrode and a saturated calomel reference cell. The titanium alloy oxides were stabilized at room temperature and ambient aeration for 1 hour. The potentiodynamic polarizations were performed over a range of potentials starting from $+0.02 \mathrm{~V}$ above the open circuit potential to $-1.5 \mathrm{~V}$ vs. SCE. The 138 138 . .

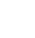
. . . . 3

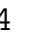




\section{Results}

\subsection{Alloy and oxide characterization}

XRD results reported previously[9] indicate that the annealing process for both Ti99Cr1 and Ti99Sn1 resulted in solid solution alloying and the minor alloying elements were incorporated into the single HCP phase. For both $\mathrm{Cr}$ and $\mathrm{Sn}$ the HCP lattice contracted, likely due to substitutional alloying of the smaller atomic radii.

\section{$\underline{\text { 3.1.1 XPS measurements }}$}

The results of the XPS measurements of the oxide composition and thickness are shown in Table 1. These values indicate that anodic polarization led to thicker oxides and increased the fraction of $\mathrm{TiO}_{2}$ vs $\mathrm{Ti}_{2} \mathrm{O}_{3}$ as compared to the ratio in a natively formed oxide while cathodic polarization

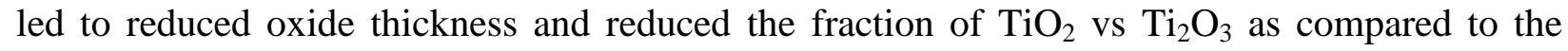
anodically polarized oxide. Note that the similar ratio of concentrations of $\mathrm{TiO}_{2}$ to $\mathrm{Ti}_{2} \mathrm{O}_{3}$ for the two cathodic potentials most likely arise because there is little $\mathrm{TiO}_{2}$ formation at these potentials at the expense of the natively formed oxide composition.

Table 1. Comparison of oxide thickness and composition as a function of formation potential.

\begin{tabular}{lccc}
\hline Oxide & Formation potential vs. SCE/V & Thickness/nm & $\mathbf{T i O}_{2} / \mathbf{T i}_{\mathbf{2}} \mathbf{O}_{\mathbf{3}}$ ratio \\
\hline Pure $\mathrm{Ti}$ & 0.1 & 8.6 & $91 \% / 9 \%$ \\
& -0.4 & 5.6 & $80 \% / 20 \%$ \\
& -1.7 & 5.2 & $82 \% / 18 \%$ \\
\hline $\mathrm{Ti}_{99} \mathrm{Sn}_{1}$ & 0.1 & 8.7 & $91 \% / 9 \%$ \\
& -0.4 & 5.9 & $83 \% / 17 \%$ \\
& -1.7 & 5.4 & $80 \% / 20 \%$ \\
\hline $\mathrm{Ti}_{99} \mathrm{Cr}_{1}$ & 0.1 & 8.5 & $90 \% / 10 \%$ \\
& -0.4 & 5.7 & $81 \% / 19 \%$ \\
& -1.7 & 5.9 & $80 \% / 20 \%$ \\
\hline
\end{tabular}

3.1.2 EIS and Mott-Schottky measurements

156 Example Bode plots of the oxide responses to three repetitions of EIS scans for pure titanium at $157+0.1,-0.4$, and $-1.7 \mathrm{~V}$ vs. SCE are shown in Figure 1. The modulus of the impedance and phase 
responses have been plotted as functions of frequency. Solution resistances, averaging $10 \Omega$, was determined from the measured response at high frequencies and capacitance and polarization resistance changes in the oxide response can be determined from the oscillating applied potential at lower frequencies. Similar sets of experiments were performed for each alloy. A three element constant phase element (CPE) equivalent circuit model, similar to a Randle's circuit, was fit to the impedance measurements to obtain solution resistance, polarization resistance, and equivalent capacitance values.

165 The inverse square of the capacitance as a function of potential for each of the oxides is shown in Figure 2. Each curve represents the average response obtained from three iterations of the experiment. In general, between $-0.3 \mathrm{~V}$ vs. SCE and $-1.0 \mathrm{~V}$ vs. SCE there was a linear relationship between potential and $1 / C^{2}$, which indicated the oxide was acting as a Schottky barrier and the Mott-Schottky relationship was expected to hold [12]. The positive slope of the response curves between $-0.3 \mathrm{~V}$ vs. SCE and $-1.0 \mathrm{~V}$ vs. SCE was indicative of an n-type semiconductor [13]. The increase in $1 / \mathrm{C}^{2}$ from $-1.4 \mathrm{~V}$ vs. SCE to $-1.6 \mathrm{~V}$ vs. SCE indicated changes in the majority charge carrier type in the semiconductor oxide, i.e. from n-type to ptype. However, because this transition occurred close to the potential at which $\mathrm{Ti}_{2} \mathrm{O}_{3}$ became thermodynamically stable with respect to $\mathrm{TiO}_{2}$, the n-type to p-type transition and the increase in 175 the fraction of $\mathrm{Ti}_{2} \mathrm{O}_{3}$ present in the oxide appeared to be related [14]. 


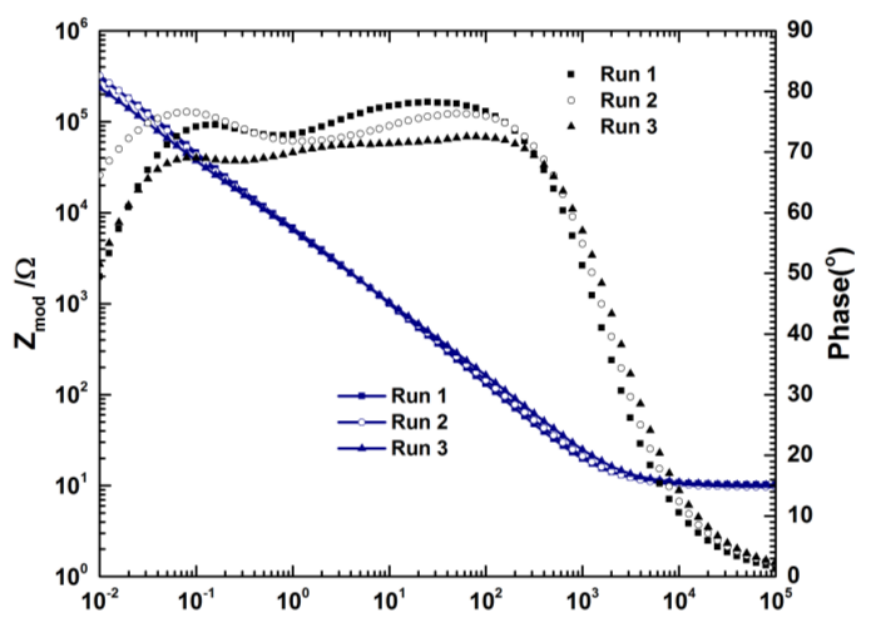

$7 a$.

Frequency/Hz

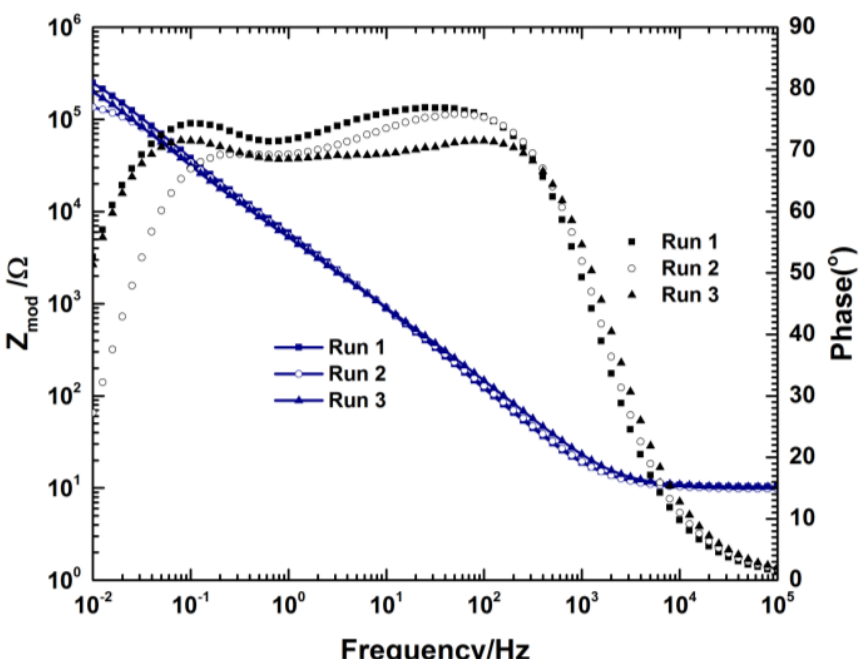

b.

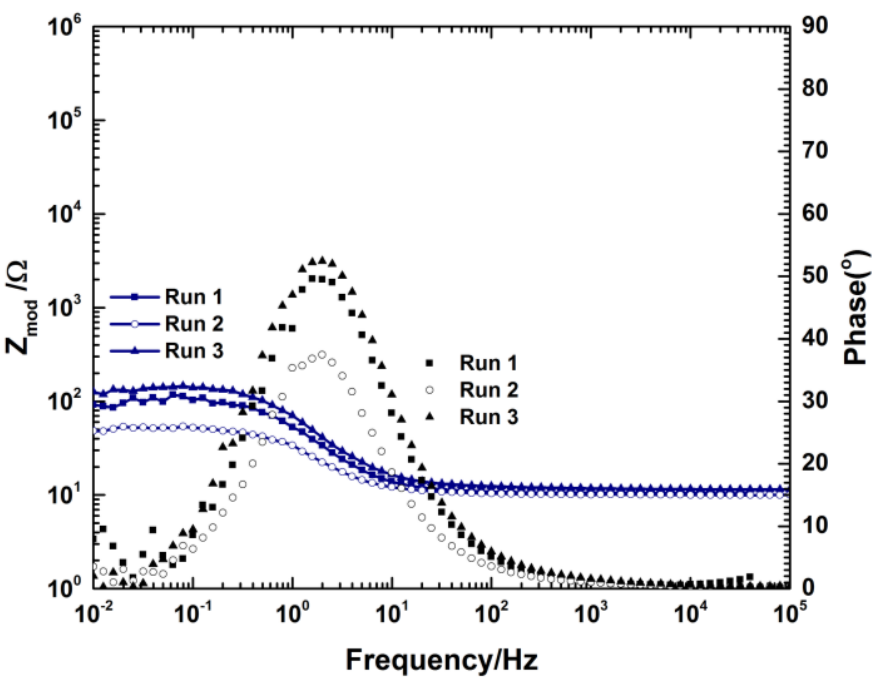

177 Figure 1. Plots of $\mathrm{Z}_{\text {mod }}$ vs. frequency (line+symbol) overlaid on plots of phase angle vs. 178 frequency (symbols only) for pure titanium oxide in in $0.6 \mathrm{M} \mathrm{NaCl}+0.01 \mathrm{M} \mathrm{NaOH}$ at 179 potentials: (a) $0.1 \mathrm{~V}$ vs. SCE, (b) $-0.4 \mathrm{~V}$ vs. SCE, and (c) $-1.7 \mathrm{~V}$ vs. SCE. The single time 
4180 constant response to the voltage perturbation suggested that a constant-phase element equivalent 181 circuit was sufficient for capturing the oxide behavior.

7

8182 
a.
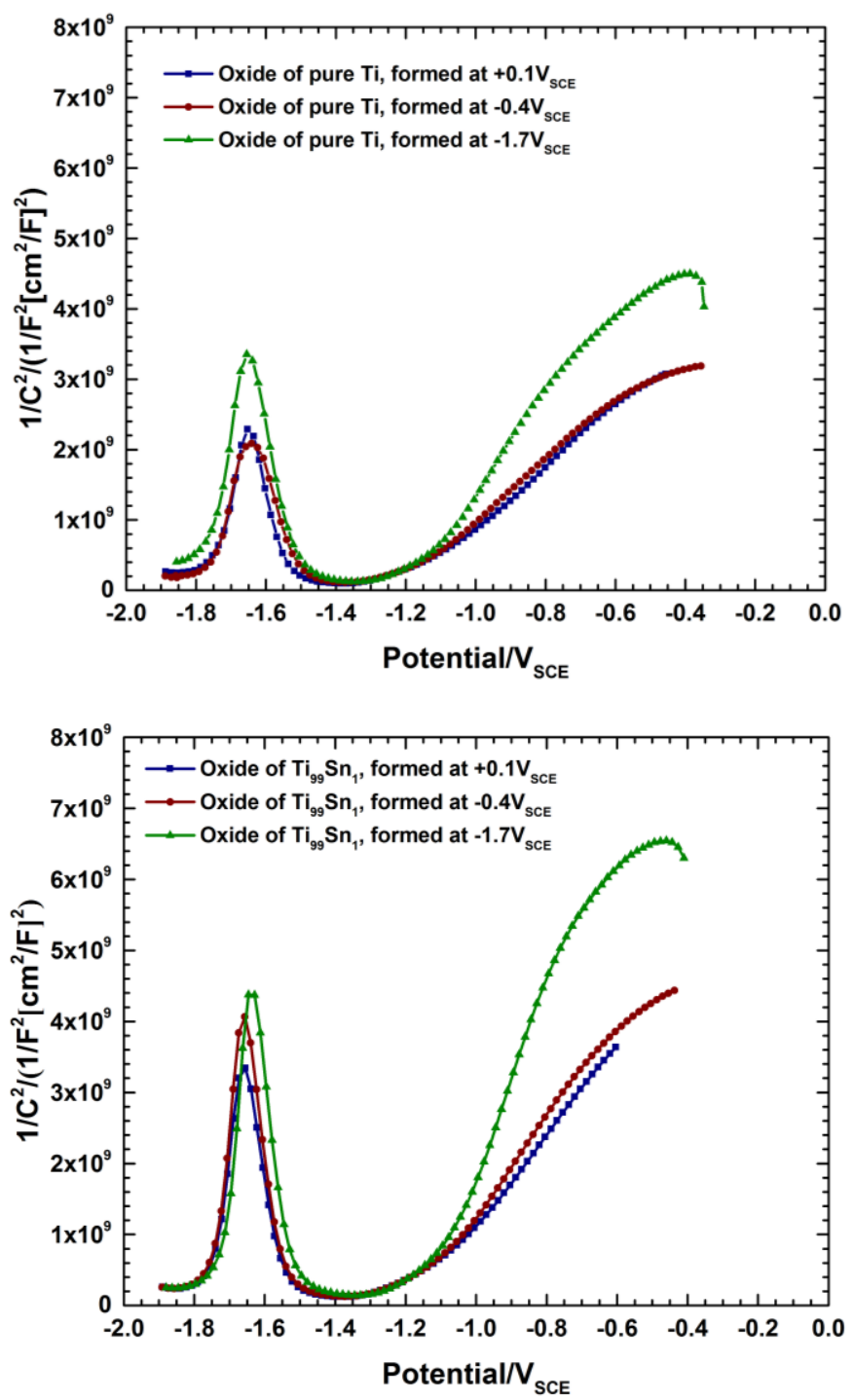

b.

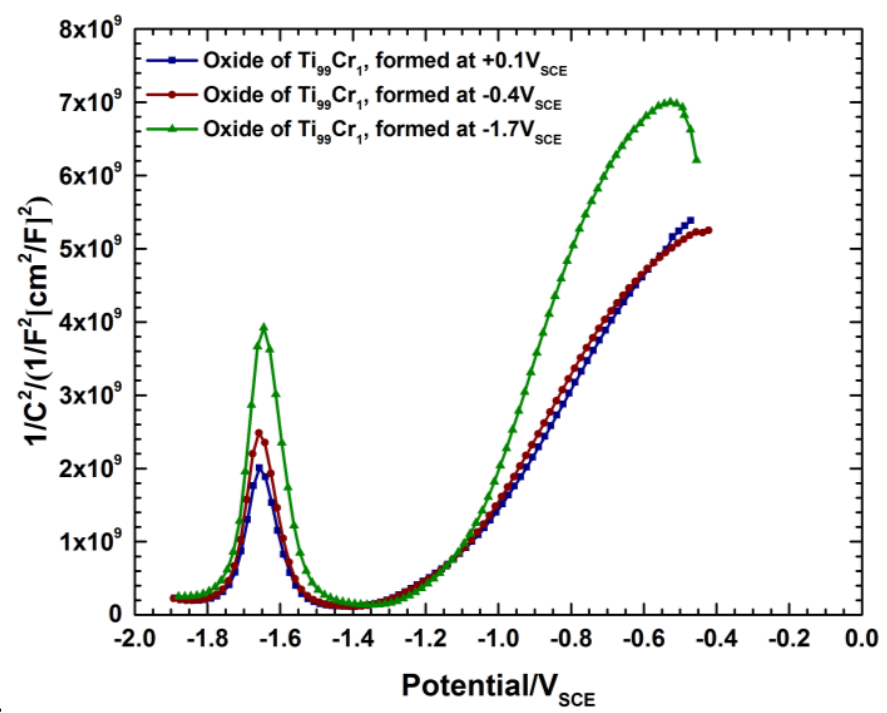


3

4183 Figure 2. Plots of $1 / \mathrm{C}^{2}$ vs. applied potential at $100 \mathrm{~Hz}$ for (a) Ti and the binary alloys: (b) $\mathrm{Ti}_{99} \mathrm{Sn}_{1}$ 5184 and (c) $\mathrm{Ti}_{99} \mathrm{Cr}_{1}$ in $0.6 \mathrm{M} \mathrm{NaCl}+0.01 \mathrm{M} \mathrm{NaOH}$ solution at oxide formation potentials of $0.1 \mathrm{~V}$ vs.

7185 SCE, $-0.4 \mathrm{~V}$ vs. SCE, and $-1.7 \mathrm{~V}$ vs. SCE. 


\subsubsection{IMPS measurements}

Examples of the photoelectrochemical response of the titanium oxide, evolved at different potentials, to a range of photon energies and light modulation frequencies is shown in Figure 3. 189 The incident photon energies are shown in ascending order of energy, on the right side: $1450 \mathrm{~nm}$ 190 to $310 \mathrm{~nm}$; spanning the infrared, visible light, and ultraviolet regions. Similar response curves 191 were obtained for all of the doped oxides. Incident photons with energies greater than the oxide 192 band gap were expected to induce photocurrents arising from either photo-generated holes or 193 excited conduction band electrons while incident photons with energies less than the band gap 194 were not expected to induce photocurrents. This trend held for the UV incident photons, which 195 had energies exceeding the band gaps of the various oxides and induced high photocurrents, and 196 the IR incident photons, which had energies far below the band gaps of the various oxides. 197 However, within the visible light region, in which the incident photons had less energy than the 198 nominal band gaps, the photocurrent response was mixed. Below $\sim 1 \mathrm{kHz}$ light modulation 199 frequency, the magnitude of the photocurrents generally decreased as the photon energies 200 decreased. Current spikes near $60 \mathrm{~Hz}$ correspond to interference from oscillations at the power 201 supply frequency. The response of the oxides to light modulation above $1 \mathrm{kHz}$ did not follow 202 any identifiable trends. 


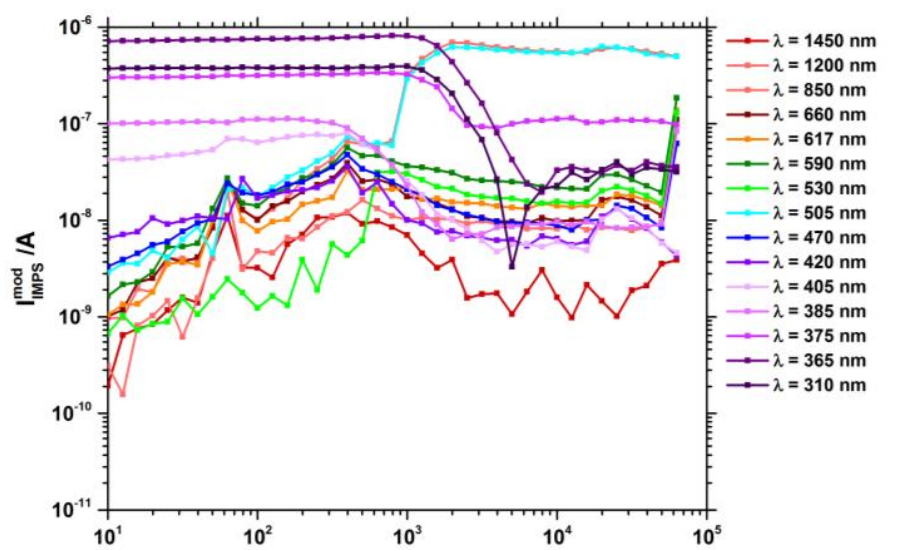

a.

Light modulation frequency/Hz

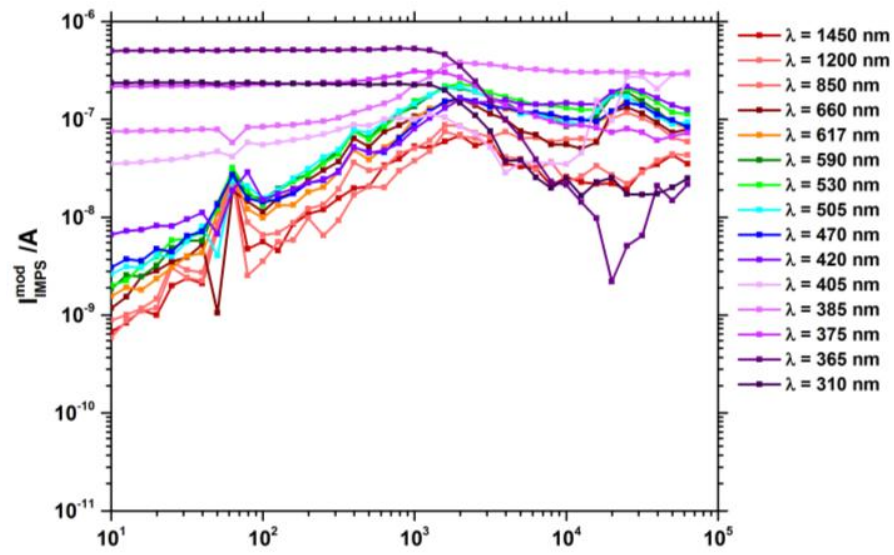

b.

Light modulation frequency/Hz

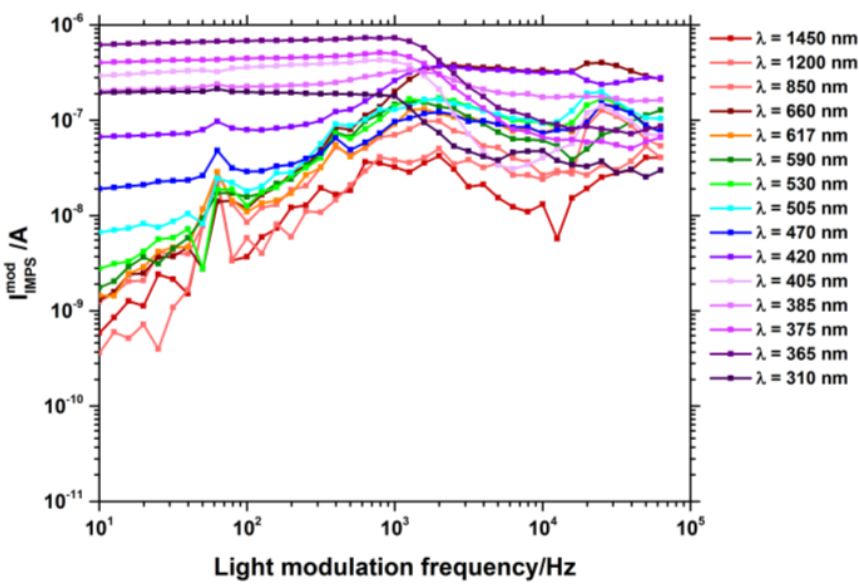
205 wavelength LED for the oxide on pure Ti at formation potentials of (a) $0.1 \mathrm{~V}$ vs. SCE, (b) $-0.4 \mathrm{~V}$ 206 vs. SCE, and (c) -1.7 V vs. SCE. 


\subsection{Electrochemical characterization}

Cathodic polarization curves for each of the oxides are shown in Figure 4. Various regions of the current response of each oxide to the applied potential are indicated on the plot, including the most likely dominant reduction reaction and the most likely controlling mechanism. Each alloy shows clear mixed activation and diffusion control regimes for oxygen reduction at potentials

213 above $-1 \mathrm{~V}$ vs. SCE and a clearly defined mass transport limited current density at potentials 214 between -1 V vs. SCE and -1.4 V vs. SCE. At potentials below -1.4 V vs. SCE, hydrogen 215 reduction provides the dominant contribution to the cathodic current. Note that the oxide formed 216 on the $\mathrm{Ti}_{99} \mathrm{Cr}_{1}$ alloy shows a slightly suppressed average hydrogen evolution current density in 217 relation to the other two materials.

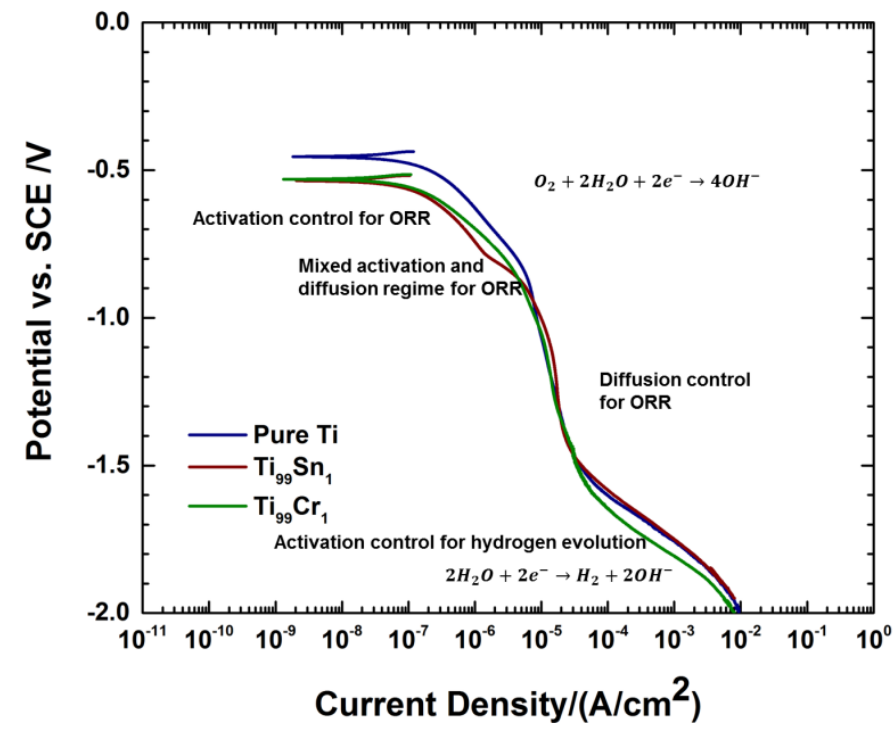

219 Figure 4. Plots of the cathodic polarization curves for Ti and the two binary alloys: $\mathrm{Ti}_{99} \mathrm{Sn}_{1}$, and $220 \mathrm{Ti}_{99} \mathrm{Cr}_{1}$, in $0.6 \mathrm{M} \mathrm{NaCl}+0.01 \mathrm{M} \mathrm{NaOH}$ solution, with regions of the current response to the 221 applied potential highlighted where different reaction mechanisms were dominant. 


\section{Discussion}

The oxide on titanium is generally considered to behave as a semiconductor with an approximate

$3.1 \mathrm{eV}$ band-gap $[15,16]$. The interface between the oxide and the electrolyte can be envisioned in the semiconductor energy level diagram in Figure 5[17, 18] and semiconductor properties of the oxides, such as the band gap, the flat band potential, and the dielectric constant, can be obtained from the EIS and Mott-Schottky experimental results.

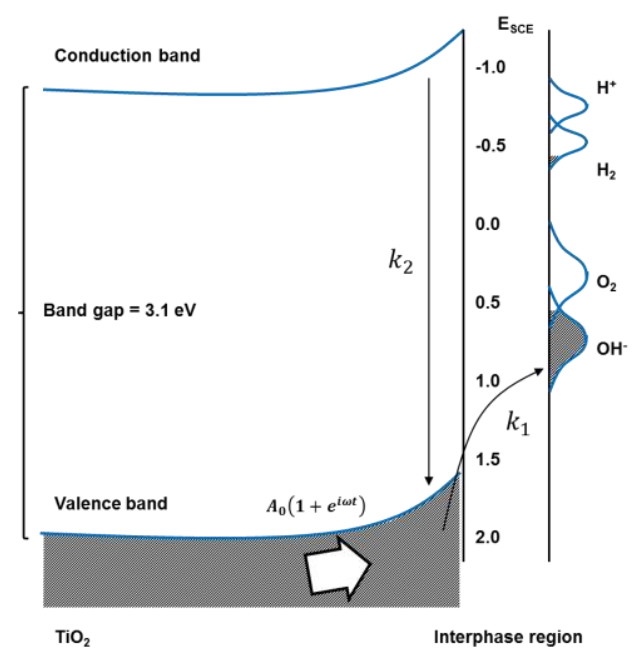

$0.6 \mathrm{M} \mathrm{NaCl}+0.01 \mathrm{M} \mathrm{NaOH}$

Figure 5. The band energy diagram for $\mathrm{TiO}_{2}$ shows the valence and conduction bands and the band gap in the oxide, the interface with the electrolyte, and approximate density of states at the interface for selected redox reactions. The shaded regions represent occupied density of states.

Because only single time constants are present in the EIS responses in Figure 1, the CPE equivalent circuit model was used to capture the behavior of the oxide. From the equivalent circuit models, values for the charge-transfer resistance, $\mathrm{R}_{\mathrm{P}}$, and the constant-phase-element parameters, $\mathrm{Y}_{0}$ and $\alpha$, were obtained for the oxides on pure $\mathrm{Ti}, \mathrm{Ti}_{99} \mathrm{Sn}_{1}$, and $\mathrm{Ti}_{99} \mathrm{Cr}_{1}$, and are 238 shown in Table 2, Table 3, and Table 4, respectively. Values for solution resistance, $\mathrm{R}_{\mathrm{U}}$, were 239 also obtained but they only varied by approximately $1 / \Omega$ from $9-10 / \Omega$ and are not shown in the 240 table. 
Table 2. Values determined from a CPE equivalent circuit model fit to EIS data obtained from pure titanium oxide along with the calculated oxide film capacitance.

\begin{tabular}{lcccc}
\hline Formation & \multicolumn{3}{c}{ Fit Parameter } & \\
\cline { 2 - 4 } potential vs. & $\alpha$ & $\mathbf{Y}_{\mathbf{0}} /\left(\mathbf{S} * \mathbf{s}^{\boldsymbol{\alpha}}\right)$ & $\mathbf{R}_{\mathbf{P}} / \mathbf{k} \Omega * \mathbf{c m}^{2}$ & \\
SCE/V & & & & \\
\hline 0.1 & 0.824 & $34.4 \times 10^{-6}$ & 881 & 111 \\
-0.4 & 0.822 & $40.0 \times 10^{-6}$ & 438 & 116 \\
-1.7 & 0.897 & $3880 \times 10^{-6}$ & 0.042 & 4790 \\
\hline
\end{tabular}

Table 3. Values determined from a CPE equivalent circuit model fit to EIS data obtained from the oxide on $\mathrm{Ti}_{99} \mathrm{Sn}_{1}$ along with the calculated oxide film capacitance.

\begin{tabular}{|c|c|c|c|c|}
\hline \multirow{2}{*}{$\begin{array}{l}\text { Formation } \\
\text { potential vs. } \\
\text { SCE/V }\end{array}$} & \multicolumn{3}{|c|}{ Fit Parameter } & \multirow[b]{2}{*}{ Capacitance $/\left(\mu \mathrm{F} / \mathrm{cm}^{2}\right)$} \\
\hline & $\alpha$ & $\mathbf{Y}_{0} /\left(\mathbf{S}^{*} \mathbf{s}^{\alpha}\right)$ & $\mathbf{R}_{\mathbf{P}} / \mathbf{k} \Omega * \mathrm{~cm}^{2}$ & \\
\hline 0.1 & 0.857 & $24.5 \times 10^{-6}$ & 575 & 62 \\
\hline-0.4 & 0.847 & $29.6 \times 10^{-6}$ & 413 & 76 \\
\hline-1.7 & 0.855 & $2820 \times 10^{-6}$ & 0.180 & 4100 \\
\hline
\end{tabular}

249 Table 4. Values determined from a CPE equivalent circuit model fit to EIS data obtained from 250 the oxide on $\mathrm{Ti}_{99} \mathrm{Cr}_{1}$ along with the calculated oxide film capacitance.

\begin{tabular}{|c|c|c|c|c|}
\hline \multirow{2}{*}{$\begin{array}{l}\text { Formation } \\
\text { potential vs. } \\
\text { SCE/V }\end{array}$} & \multicolumn{3}{|c|}{ Fit Parameter } & \multirow[b]{2}{*}{ Capacitance $/\left(\mu \mathrm{F} / \mathrm{cm}^{2}\right)$} \\
\hline & $\alpha$ & $\mathbf{Y}_{0} /\left(\mathbf{S}^{*} \mathbf{s}^{\alpha}\right)$ & $\mathbf{R}_{\mathbf{P}} / \mathrm{k} \Omega * \mathrm{~cm}^{2}$ & \\
\hline 0.1 & 0.814 & $31.3 \times 10^{-6}$ & 919 & 101 \\
\hline-0.4 & 0.800 & $38.6 \times 10^{-6}$ & 662 & 130 \\
\hline-1.7 & 0.894 & $2670 \times 10^{-6}$ & 0.130 & 3380 \\
\hline
\end{tabular}


In addition, using equation (9), values for double-layer capacitance were calculated and are listed in the final column of each of the tables [19].

$$
C=\frac{\left(Y_{0} R_{p}\right)^{\frac{1}{\alpha}}}{R_{p}}
$$

$C$ represented the double-layer capacitance, $R_{P}$ the charge transfer resistance, $Y_{0}$ was the magnitude of the CPE[20], and $\alpha$ represented an empirical constant to capture the deviation of the CPE from an ideal capacitor. Note that the capacitance increased for each of the oxides when the formation potential changed from $0.1 \mathrm{~V}$ vs. SCE to $-0.4 \mathrm{~V}$ vs. SCE, but that there was a twoorders of magnitude increase after the oxide was exposed to a potential of $-1.7 \mathrm{~V}$ vs. SCE; a potential at which $\mathrm{Ti}_{2} \mathrm{O}_{3}$ was thermodynamically favored to form at the expense of $\mathrm{TiO}_{2}$ and which was detected in the XPS results. These values suggest that the oxides were becoming more defective at the more cathodic potentials.

263 The Mott-Schottky relationship [21, 22], equation (10), was employed to determine the flat band 264 potential and defect concentrations of the oxides.

$$
\frac{1}{C^{2}}=\frac{2 *\left(V_{a p p}-E_{F B}-\frac{k_{B} T}{e}\right)}{\epsilon \epsilon_{0} e N_{D} A^{2}}
$$

where $E_{F B}$ is the flat band potential, $C$ is the interfacial capacitance, $\mathrm{e}$ is the charge on the electron, $\mathrm{A}$ is the interfacial contact area, $\varepsilon$ is the dielectric constant of the oxide, $\varepsilon_{0}$ is vacuum permittivity, and $\mathrm{V}_{\mathrm{app}}$ is the externally applied potential. The Mott-Schottky equation proposes an inverse relationship between capacitance and applied potential with the slope related to the defect concentration, $\mathrm{N}_{\mathrm{D}}$.

271 The dielectric constants, $\varepsilon$, for the oxides were obtained from equation (11).

$$
C=\frac{\epsilon \epsilon_{0} A}{D}
$$


where $\mathrm{C}$ is the resistance-corrected capacitance [23], $\varepsilon$ is the dielectric constant of the oxide, $\varepsilon_{0}$ is vacuum permittivity, and $A$ is the exposed area, and D is the oxide thickness[24]. The exposed areas were approximately $0.69 / \mathrm{cm}^{2}, 0.66 / \mathrm{cm}^{2}$, and $0.72 / \mathrm{cm}^{2}$ for the pure Ti, $\mathrm{Ti}_{99} \mathrm{Sn}_{1}$, and $\mathrm{Ti}_{99} \mathrm{Cr}_{1}$ oxides, respectively. The oxide thicknesses were estimated by XPS sputtering. Using the capacitance values estimated from plots of $\mathrm{C}_{\text {real }}$ vs. frequency calculated from the EIS data, the dielectric constants in Table 5 were obtained:

Table 5. Oxide thicknesses obtained from XPS analysis and calculated dielectric constants for the metal oxides as a function of the oxide formation potential.

\begin{tabular}{lcccc}
\hline $\begin{array}{l}\text { Metal } \\
\text { Oxide }\end{array}$ & $\begin{array}{c}\text { Formation potential } \\
\text { vs. SCE/V }\end{array}$ & $\begin{array}{c}\text { Corrected } \\
\text { capacitance/nF }\end{array}$ & $\begin{array}{c}\text { Oxide thickness } \\
\text { /nm }\end{array}$ & $\begin{array}{c}\text { Dielectric } \\
\text { Constant }\end{array}$ \\
\hline Pure $\mathrm{Ti}$ & 0.1 & 750 & 8.6 & 106 \\
& -0.4 & 820 & 5.6 & 74 \\
& -1.7 & 12 & 5.2 & 0.11 \\
$\mathrm{Ti}_{99} \mathrm{Sn}_{1}$ & 0.1 & 620 & 8.7 & 92 \\
& -0.4 & 760 & 5.9 & 77 \\
& -1.7 & 2 & 5.4 & 0.02 \\
$\mathrm{Ti}_{99} \mathrm{Cr}_{1}$ & 0.1 & 531 & 8.5 & 71 \\
& -0.4 & 540 & 5.7 & 48 \\
& -1.7 & 4 & 5.9 & 0.03 \\
\hline
\end{tabular}

282 The donor concentration was determined by manipulating (10) to obtain:

$$
\text { Slope }=\frac{2}{\epsilon \epsilon_{0} e A^{2} N_{D}}
$$

284 where the slope is from the linear best-fit line to the $1 / \mathrm{C}^{2}$ vs. potential plot for each oxide from 285 the Mott-Schottky measurements. The flat band potential were also obtained by manipulating 286 equation (10) to arrive at:

$$
V_{a p p}=E_{F B}+\frac{k_{B} T}{e}
$$


287 The flat band potentials, shown in Table 6, are consistent with $\mathrm{TiO}_{2}$ values published in the literature and with each other. The defect concentrations, $\mathrm{N}_{\mathrm{D}}$, of the oxides formed at $0.1 \mathrm{~V}$ vs. SCE and -0.4 V vs. SCE are approximately equal to the published values of defect concentrations in $\mathrm{TiO}_{2}$ of $\mathrm{N}_{\mathrm{D}} \approx 3 \times 10^{20} / \mathrm{cm}^{-3}$ [25]. There was a clear trend, however, that, as the formation potential was decreased, the defect concentration also increased until, for the oxides exposed to the $-1.7 \mathrm{~V}$ vs. SCE potential, the defect concentrations were two orders of magnitude higher than the expected value. The defect concentrations were likely increasing because the $0.4 \mathrm{~V}$ vs. SCE potentials drove changes in the $\mathrm{TiO}_{2}$ structure and at $-1.7 \mathrm{~V}$ vs. SCE, the applied potential was driving the formation of a highly defective $\mathrm{Ti}_{2} \mathrm{O}_{3}$ oxide.

Table 6. Values for $\mathrm{E}_{\mathrm{FB}}$, the flat band potential, and the defect concentration, $\mathrm{N}_{\mathrm{D}}$, determined from analysis of the Mott-Schottky tests performed on the pure titanium oxide and oxides of titanium alloys, as a function of the oxide formation potential.

\begin{tabular}{lccc}
\hline Metal Oxide & Formation potential vs. & $\mathbf{E}_{\mathbf{F B}} \mathbf{v s .} \mathbf{S C E} / \mathbf{V}$ & $\mathbf{N}_{\mathbf{D}} / \mathbf{c m}^{\mathbf{- 3}}$ \\
\hline PCE/V & 0.1 & -1.2 & $6.2 \times 10^{20}$ \\
& -0.4 & -1.2 & $8.7 \times 10^{20}$ \\
& -1.7 & -1.2 & $3.5 \times 10^{23}$ \\
$\mathrm{Ti}_{99} \mathrm{Sn}_{1}$ & 0.1 & -1.3 & $5.4 \times 10^{20}$ \\
& -0.4 & -1.3 & $5.7 \times 10^{20}$ \\
& -1.7 & -1.2 & $14 \times 10^{23}$ \\
$\mathrm{Ti}_{99} \mathrm{Cr}_{1}$ & 0.1 & -1.2 & $4.5 \times 10^{20}$ \\
& -0.4 & -1.2 & $6.5 \times 10^{20}$ \\
& -1.7 & -1.1 & $5.1 \times 10^{23}$ \\
\hline
\end{tabular}

300 The flat band potentials fix the lower bound of the conduction band in the n-type semiconductor oxides but the band gaps are also needed to determine the top edge of the valence bands. The response of the oxide films to the IMPS experiments, as shown in Figure 3, was used to determine the band gaps. As the incident photon energies transitioned from the UV-portion of the spectrum into the visible light region, the photocurrents dropped rapidly to negligible values. Linear fits to the photocurrents normalized to account for variation in photon irradiance at the sample, shown in Figure 6, provided the estimates of the band gap energies[26]. 
a.
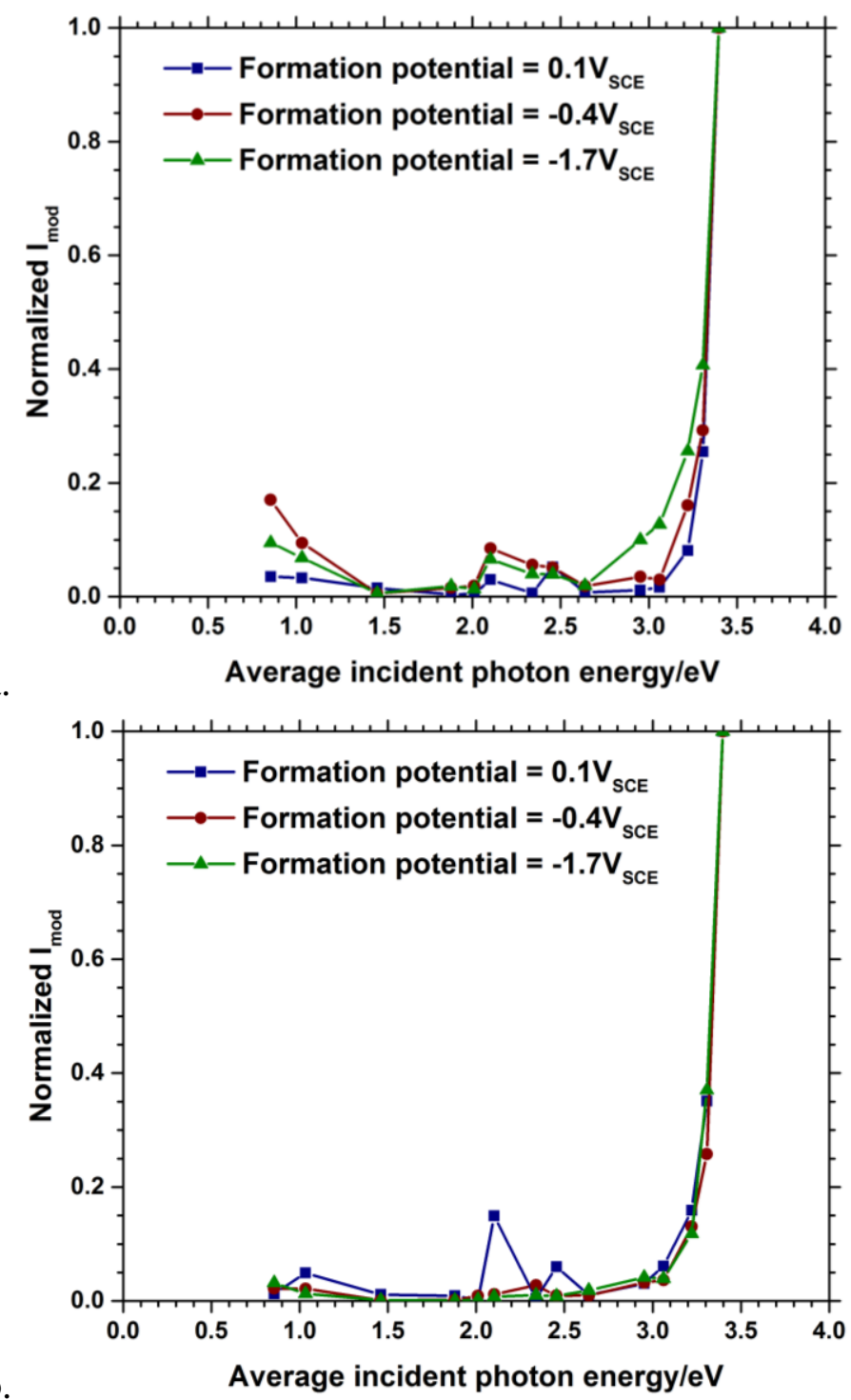

b.

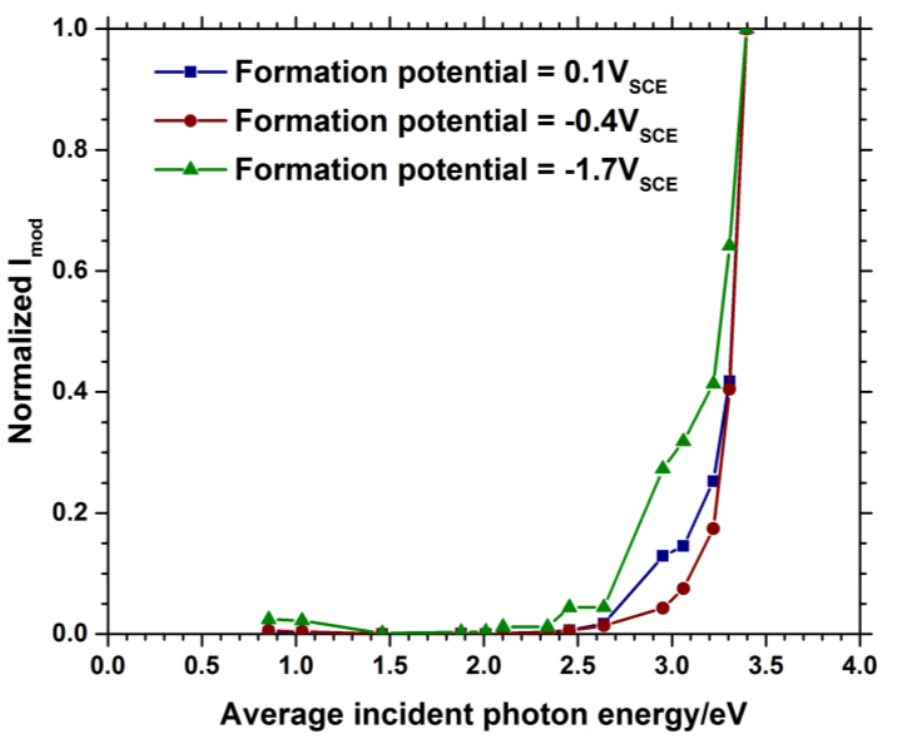


Figure 6. Normalized photocurrent response as a function of photon energy for oxides formed at $0.1 \mathrm{~V}$ vs. SCE, $-0.4 \mathrm{~V}$ vs. SCE, and $-1.7 \mathrm{~V}$ vs. SCE for (a) Ti, (b) $\mathrm{Ti}_{99} \mathrm{Sn}_{1}$, and (c) $\mathrm{Ti}_{99} \mathrm{Cr}_{1}$.

The band gaps obtained from this approach [27] were in keeping with the accepted band gap of $3.1 \mathrm{eV}$ for rutile $\mathrm{TiO}_{2}$. The tops of the valence band energies were then obtained by subtracting 312 the band gap energy from the base of the conduction band energies, with those results shown in 313 Table 7. The cathodic polarizations did not appreciably alter the band gaps; with the exception 314 of the polarization at $-1.7 \mathrm{~V}$ vs. SCE for the $\mathrm{Ti}_{99} \mathrm{Cr}_{1}$ oxide. The apparent narrowing of the band 315 gap occurs from the response seen in Figure 6c, which may arise from the development of 316 surface states in the oxides resulting from the formation of $\mathrm{Ti}_{2} \mathrm{O}_{3}[28]$ and which could account 317 for the slight suppression in the hydrogen evolution reaction on the $\mathrm{Ti}_{99} \mathrm{Cr}_{1}$ oxide.

319 Table 7. Values for the band gap energies and valence band energies for titanium oxide and the 320 oxides of the titanium alloys.

\begin{tabular}{lccc}
\hline Metal Oxide & $\begin{array}{c}\text { Formation potential vs. } \\
\text { SCE/V }\end{array}$ & $\mathbf{E g}_{\mathbf{g}} / \mathbf{e V}$ & EV \\
\hline Pure Ti & 0.1 & 3.2 & 2.0 \\
& -0.4 & 3.1 & 1.9 \\
& -1.7 & 3.1 & 1.9 \\
$\mathrm{Ti}_{99} \mathrm{Sn}_{1}$ & 0.1 & 3.1 & 1.9 \\
& -0.4 & 3.1 & 1.9 \\
& -1.7 & 3.1 & 2.0 \\
$\mathrm{Ti}_{99} \mathrm{Cr}_{1}$ & 0.1 & 3.1 & 1.9 \\
& -0.4 & 3.1 & 1.9 \\
& -1.7 & 2.9 & 1.8 \\
\hline
\end{tabular}


The above analysis indicated that different formation potentials induced only minor shifts in the band structure and band gaps and that, as shown in Figure 5, both the hydrogen evolution reaction and the oxygen reduction reaction from equation (1) were thermodynamically allowed on these oxides at this $\mathrm{pH}$ [29]. Thus, the variance in the semiconductor properties of the different oxides appears to be insufficient to account for the catalytic differences in the oxide behaviors observed in the potentiodynamic polarization experiments.

The photoelectrochemical responses of the oxides, on the other hand, demonstrated a greater range of variability. Nyquist representations of the photoelectrochemical responses are shown in Figure 7. The imaginary component of the photocurrent arises from a phase shift in the photocurrent offset from the incident light modulation frequency. Figure 7 shows $\mathrm{I}_{\text {imag }} \mathrm{vs}$. $\mathrm{I}_{\mathrm{real}}$ for responses of the oxides for each alloy formed at $0.1 \mathrm{~V}$ vs. SCE, $-0.4 \mathrm{~V}$ vs. SCE, and $-1.7 \mathrm{~V}$ vs. SCE to $365 \mathrm{~nm}$ wavelength UV light with modulation frequencies from $5000 \mathrm{~Hz}$ to $10 \mathrm{~Hz}$. For the majority of the light modulation frequencies, the imaginary component of the photocurrent response was negative, which was attributed to the space-charge capacitance of the oxide [30]. Note that the overall magnitudes of the photocurrents were smaller for the alloy oxides than for the pure titanium oxide, which suggested that the oxides on the alloys have slower reaction kinetics than for the oxide on pure Ti. Note, as well, that for the oxides of pure $\mathrm{Ti}$ and $\mathrm{Ti}_{99} \mathrm{Sn}_{1}$ exposed to the $-1.7 \mathrm{~V}$ vs. SCE potential, the photocurrents responses were higher in magnitude than for the oxides exposed to the $-0.4 \mathrm{~V}$ vs. SCE potential and for the oxide on $\mathrm{Ti}_{99} \mathrm{Cr}_{1}$, the photocurrent responses were nearly identical. This suggests that once the formation of $\mathrm{Ti}_{2} \mathrm{O}_{3}$ was thermodynamically favored, the oxides became more active with respect to catalyzing the ORR. 


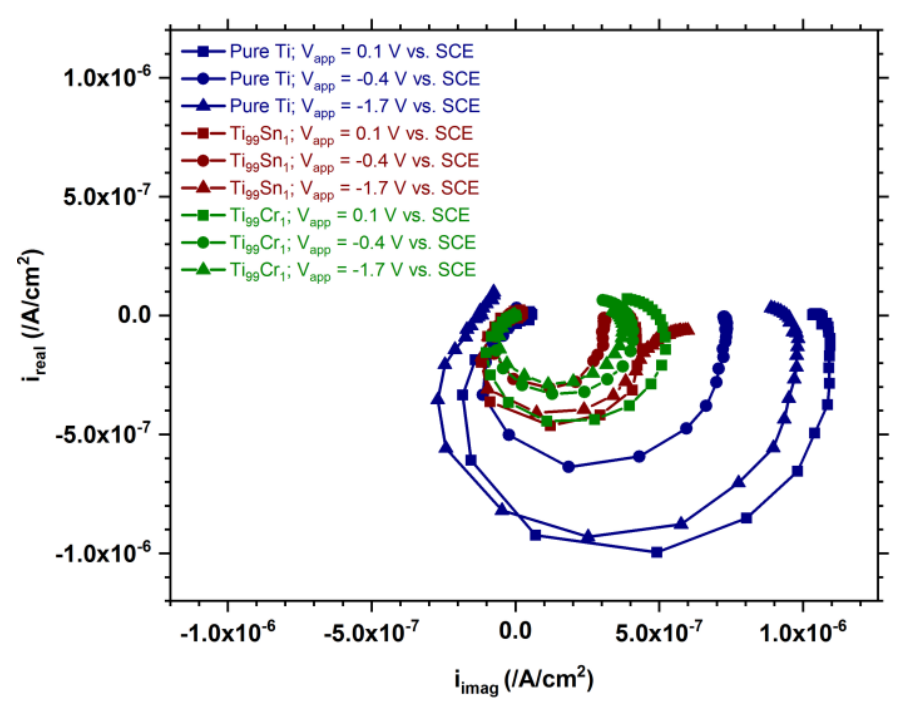

347 Figure 7. Nyquist plot of $\mathrm{I}_{\text {imag }}$ vs. $\mathrm{I}_{\text {real }}$ for oxides formed at 0.1 V vs. SCE, -0.4 V vs. SCE, and $348 \quad 1.7 \mathrm{~V}$ vs. SCE in pure $\mathrm{Ti}, \mathrm{Ti}_{99} \mathrm{Sn}_{1}$, and $\mathrm{Ti}_{99} \mathrm{Cr}_{1}$.

349 A kinetic model of the oxide behavior in response to photo-excitation was developed following 350 the Ponomarev-Peter approach [31-33] and was used to predict charge transport in the oxide 351 band structure. From the band diagram in Figure 5, it can be supposed that incident photons, with 352 energy greater than the band gap, will excite electrons from the valence band into the conduction 353 band, leaving positively charged holes behind, shown as equations (17) and (18). Once in the 354 conduction band, some of the electrons recombine with the holes [34], at a rate $\mathrm{k}_{2}$, and are lost 355 while the majority will be transported through the external circuit to the counter electrode [35]. 356 Only a few will be able to travel to the interface to participate in a reduction reaction. The 357 valence band holes, on the other hand, have much lower mobility than the electrons and, those 358 that are not extinguished due to recombination, will reach the oxide-electrolyte interface and help 359 drive water oxidation or other available reactions [36] at a rate, $\mathrm{k}_{1}$. The governing equations are 360 written as the following:

$$
\begin{gathered}
\frac{q_{S}}{C_{S}}+\frac{q_{H}}{C_{H}}=I_{\text {ext }} R \\
\frac{d q_{S}}{d t}=A_{0}\left(1+e^{i \omega t}\right)-I_{\text {ext }}-k_{2}\left(q_{S}-q_{H}\right)
\end{gathered}
$$




$$
\frac{d q_{H}}{d t}=k_{1}\left(q_{S}-q_{H}\right)-I_{e x t}
$$

361 where $\mathrm{q}_{\mathrm{S}}$ is the charge transported across the space-charge region of the oxide, $\mathrm{C}_{\mathrm{S}}$ is the 362 capacitance of the space charge region, $\mathrm{q}_{\mathrm{H}}$ is the charge transported across the Helmholtz region

of the electrolyte, and $\mathrm{C}_{\mathrm{H}}$ is the capacitance of that region. $\mathrm{I}_{\mathrm{ext}}$ is the current through the external circuit, $\mathrm{R}$ is the total series resistance in the electrolyte, oxide, and electrical contacts, $\mathrm{A}_{0}$ is the magnitude of the photo-generated hole current - determined by photon irradiance on the sample and the ability of the oxide to absorb photons, $\omega$ is the light modulation frequency, $\mathrm{k}_{2}$ is the recombination rate constant, and $\mathrm{k}_{1}$ is the rate constant for photo-generated hole transfer across the interface from the valence band. The flux of holes into the interface region in response to the modulated light is given by[37]:

$$
A=A_{0}\left(1+e^{i \omega t}\right)
$$

where

$$
A_{0}=I_{0}\left(1-\frac{e^{-\frac{\alpha}{W}}}{1+\alpha L_{p}}\right)
$$

371 where $\mathrm{I}_{0}$ is the incident photon flux, $\alpha$ is the absorption coefficient, $\mathrm{Lp}$ is the diffusion length for 372 holes, and $\mathrm{W}$ is the width of the space-charge region.

373 Taking the Laplace transform of the equations in (14) - (16) gives:

$$
\begin{gathered}
\left(s+k_{2}\right) Q_{1}-k_{2} Q_{2}+I_{S}=\frac{A_{0}}{s}+\frac{A_{0}}{s-i \omega} \\
-k_{1} Q_{1}+\left(s+k_{1}\right) Q_{2}+I_{S}=0 \\
\frac{1}{C_{1}} Q_{1}+\frac{1}{C_{2}} Q_{2}-I_{S} R=0
\end{gathered}
$$

The expression for the external current, obtained from solving (19)-(21) and simplifying, is:

$$
I_{\text {ext }}(t)=\left[\frac{A_{0} k_{1}}{k_{1}+k_{2}}\right]
$$




$$
\begin{aligned}
&+\left[\frac{A_{0}}{\left(k_{1}+k_{2}+i \omega\right)}\right]\left\{\frac{2\left(k_{1}+\frac{i \omega C}{C_{S}}\right)}{1+i \omega \tau}\right\} e^{i \omega t} \\
&-\left[\frac{1}{\left(k_{1}+k_{2}+i \omega\right)}\right]\left\{\frac{\left(\frac{C}{C_{H}} k_{1}-\frac{C}{C_{S}} k_{2}\right)\left(k_{1}+k_{2}+A_{0}\left(k_{1}+k_{2}+i \omega\right)\right)}{\left(1+\tau\left(k_{1}+k_{2}\right)\right)\left(k_{1}+k_{2}\right)} e^{\left(k_{1}+k_{2}\right) t}\right\} \\
&+\left[\frac{2\left(C_{S} R k_{1}+1\right)\left(i\left(1+A_{0}\right)+A_{0} \tau \omega\right)}{(i \omega \tau-1)\left(1+\tau\left(k_{1}+k_{2}\right)\right)}\right] C_{H} e^{\frac{t}{\tau}}
\end{aligned}
$$

375 where

$$
C=\frac{C_{S} C_{H}}{C_{S}+C_{H}}
$$

376 and

$$
\tau=R C
$$

377 The oscillating component of the photocurrent is obtained from the second term in (22):

$$
I_{\text {ext }}(\omega)=\left[\frac{A_{0}}{\left(k_{1}+k_{2}+i \omega\right)}\right]\left\{\frac{2\left(k_{1}+\frac{i \omega C}{C_{S}}\right)}{1+i \omega \tau}\right\}
$$

378 The plots in Figure 8 overlay the predicted response, $\mathrm{I}_{\mathrm{ext}}(\omega)$, obtained from parameters inserted 379 into equation (25), with the measured $I_{\text {mod }}$ response for each of the alloys when exposed to UV 380 light at $365 \mathrm{~nm}$ and light modulations from $5000 \mathrm{~Hz}$ to $10 \mathrm{~Hz}$. The parameters for each predicted 381 response are found in Table 8 with the values for the capacitance of the space charge region and 382 the Helmholtz capacitance obtained from the area-corrected impedance results found in Table 2 383 Table 5. The total series resistance, $\mathrm{R}$, is an estimate of the resistance of the electrolyte, hole 384 conduction resistance in the oxide valence band, and electrical contacts. The parameters $\mathrm{k}_{1}$ and $385 \quad \mathrm{k}_{2}$ are adjusted to fit the predicted response with the measured response.

386 For light modulation frequencies above $1 \mathrm{kHz}$, the model overestimates the measured response; likely because there are fast reactions occurring at the actual interface that were not included in the reaction constants in the model. However, the predicted responses and the measured 
390 this regime, a comparison of the $\mathrm{k}_{1}$ reaction rates for the oxides formed at $0.1 \mathrm{~V}$ vs. SCE and -0.4

391 V vs. SCE - assuming the electron-hole recombination rates, $\mathrm{k}_{2}$, are constant at $2000 \mathrm{~s}^{-1}$ across 392 the oxides - shows that the reaction kinetics on the oxides on the alloys are approximately 70$39380 \%$ slower than on the oxide on pure Ti.

394 The theoretical model for the oxygen reduction reaction on titanium oxide, given in (2)-(6), with 395 the transition from surface peroxide formation to surface oxide formation, (5), generally held to 396 be the rate-determining step [38]. The experimental results and IMPS model presented here 397 support the original theoretical models of the "volcano" curve that suggested that $\mathrm{Cr}$ and $\mathrm{Sn}-$ 398 containing oxides, having higher adsorption energies for intermediate reaction products of the 399 ORR, will suppress ORR kinetics on these oxides [8, 39]. For the oxides polarized at $-1.7 \mathrm{~V}$ vs. 400 SCE, the reaction rates for electron-hole recombination and interfacial reactions increased for all 401 the oxides. However, the interfacial reaction rates for the oxides on the alloys were still lower 402 than for the oxide on pure Ti. conport the original theoretical models of the "vocano" curve that suggested that Cr and Sn- 
a.

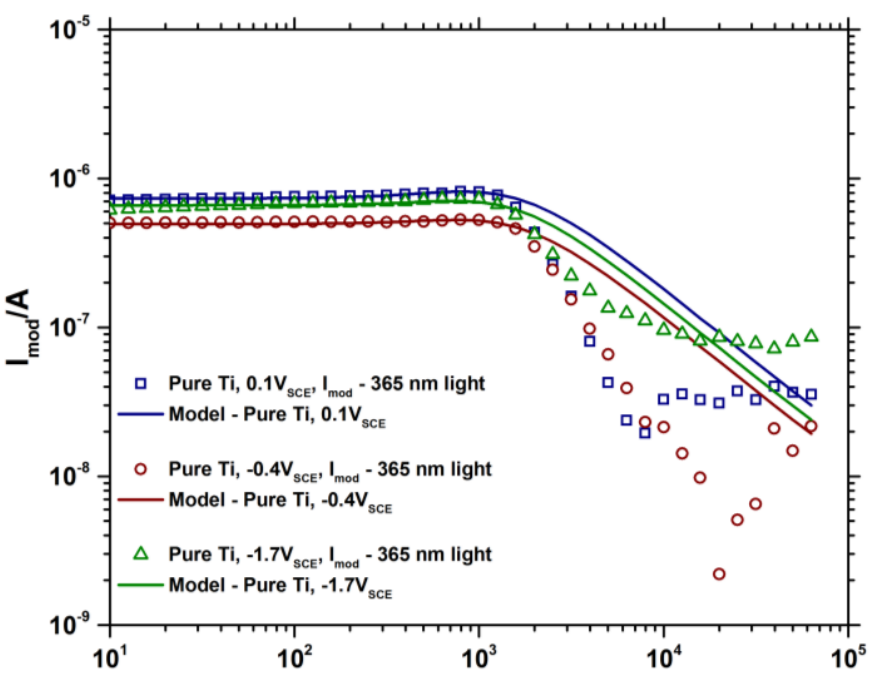

Frequency/Hz

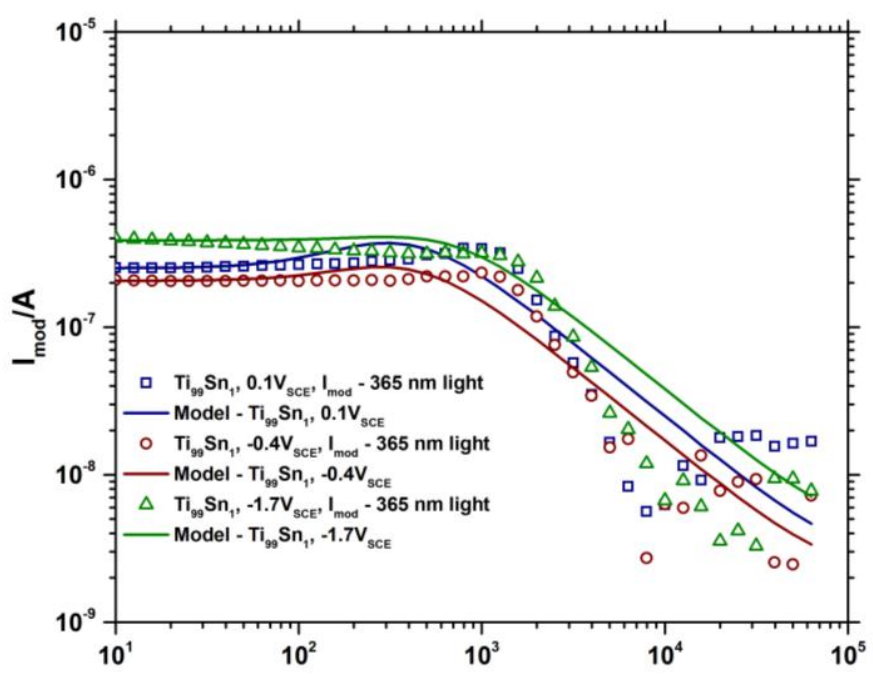

b.

Frequency/Hz

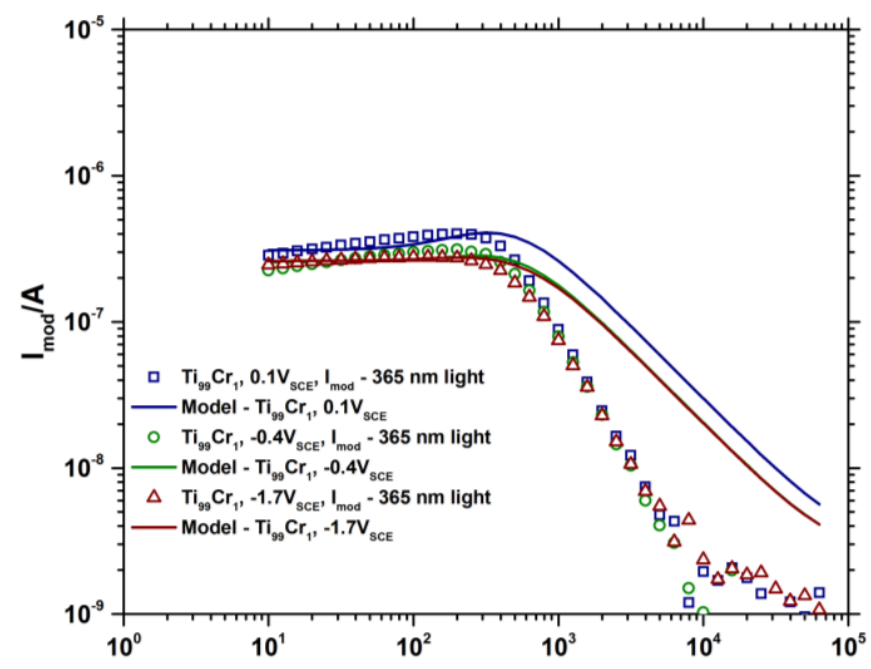

c.

Frequency $/ \mathrm{Hz}$ 


09

(

(5)

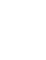

(7)

.

3

5

1

Figure 8. Bode plots of $\mathrm{I}_{\text {mod }} \mathrm{vs.} \mathrm{light} \mathrm{modulation} \mathrm{frequency} \mathrm{for} \mathrm{oxides} \mathrm{of} \mathrm{(a)} \mathrm{Ti}$, (b) $\mathrm{Ti}_{99} \mathrm{Sn}_{1}$, and (c) $\mathrm{Ti}_{99} \mathrm{Cr}_{1}$ formed at potentials of $0.1 \mathrm{~V}$ vs. SCE, $-0.4 \mathrm{~V}$ vs. SCE, and $-1.7 \mathrm{~V}$ vs. SCE, overlaid with model predictions obtained from the model expressed in equation (24). 
Table 8. Fit parameters for model predictions of the photocurrent response for each of the oxides in Figure 8.

\begin{tabular}{|c|c|c|c|c|c|c|c|c|c|}
\hline \multirow[b]{4}{*}{ Parameter } & \multicolumn{9}{|c|}{ Oxide } \\
\hline & \multicolumn{3}{|c|}{ Pure Ti } & \multicolumn{3}{|c|}{$\mathbf{T i}_{99} \mathrm{Sn}_{1}$} & \multicolumn{3}{|c|}{$\mathbf{T i}_{99} \mathrm{Cr}_{1}$} \\
\hline & \multicolumn{9}{|c|}{ Formation potential vs. SCE/V } \\
\hline & 0.1 & -0.4 & -1.7 & 0.1 & -0.4 & -1.7 & 0.1 & -0.4 & -1.7 \\
\hline $\mathrm{k}_{1} / \mathrm{s}^{-1}$ & 3500 & 4000 & 4000 & 550 & 700 & 1500 & 750 & 1000 & 900 \\
\hline $\mathrm{k}_{2} / \mathrm{s}^{-1}$ & 2000 & 2000 & 3000 & 2000 & 2000 & 3000 & 2000 & 2000 & 3000 \\
\hline $\mathrm{R} / \mathrm{K} \Omega$ & 0.22 & 0.13 & 12 & 1.4 & 1.3 & 270 & 1.3 & 1.1 & 220 \\
\hline $\mathrm{C}_{\mathrm{S}} / \mu \mathrm{F}$ & 0.75 & 0.82 & 0.012 & 0.62 & 0.76 & 0.002 & 0.53 & 0.54 & 0.004 \\
\hline $\mathrm{C}_{\mathrm{H}} / \mu \mathrm{F}$ & 77 & 80 & 3310 & 41 & 50 & 2710 & 73 & 94 & 2430 \\
\hline
\end{tabular}

413 Measurements of the oxygen reduction reaction kinetics on each of the oxide surfaces using 414 potentiodynamic polarization, as shown in Figure 4, indicate that the addition of these alloying 415 elements suppressed the ORR. For example, at $-0.8 \mathrm{~V}$ vs. SCE, a potential at which the oxygen 416 reduction reaction would occur on these oxides, the currents obtained from the cathodic 417 polarization experiments, summarized in Table 9, show that the cathodic current can be 418 suppressed approximately $30-60 \%$ in a high $\mathrm{pH}$ environment.

420 Table 9. Comparison of reduction currents on the oxides of pure $\mathrm{Ti}, \mathrm{Ti}_{99} \mathrm{Sn}_{1}$, and $\mathrm{Ti}_{99} \mathrm{Cr}_{1}$ at -0.8 $421 \mathrm{~V}$ vs. SCE in $0.6 \mathrm{M} \mathrm{NaCl}+0.01 \mathrm{M} \mathrm{NaOH}$ taken from the polarization curves.

\begin{tabular}{lc}
\hline Oxide & Reduction current/(A/cm $)$ \\
\hline Pure $\mathrm{Ti}$ & $4.1 \times 10^{-6}$ \\
$\mathrm{Ti}_{99} \mathrm{Cr}_{1}$ & $2.8 \times 10^{-6}$ \\
$\mathrm{Ti}_{99} \mathrm{Sn}_{1}$ & $1.7 \times 10^{-6}$ \\
\hline
\end{tabular}




\section{Summary and Conclusions}

The oxide that forms on titanium is generally cathodic to the majority of steel and aluminum engineering alloys and so can contribute to galvanic corrosion under some environmental conditions. However, the experimental results presented above indicate that alloying titanium with low concentrations of certain other metals can reduce ORR kinetics on the oxide and thereby suppress galvanic corrosion. Previous work [9] examined the effect on cathodic kinetics of alloying low concentrations of several elements in titanium on natively formed oxides. This report focused on the effect of formation potential along with alloying on the ability of the oxide to catalyze reactions.

433 The results presented above support the hypothesis that the additions of the minor alloying 434 elements to the alloy were incorporated into the oxide, as shown by the XPS measurements, and 435 their presence altered the electrochemical behavior of the oxide without substantially changing 436 its composition or semiconductor properties when the oxide was formed under potential control. 437 However, an important caveat to this conclusion is that the oxide had to be exposed to a potential 438 that remained in the potential-pH region in which $\mathrm{TiO}_{2}$ was thermodynamically stable. Exposing 439 the oxide to cathodic potentials at which $\mathrm{Ti}_{2} \mathrm{O}_{3}$ was favored to form introduced changes in the 440 oxide capacitance and polarization resistance and shortened the band gap while increasing the 441 ORR catalytic capability of the oxide.

442 However, because the physical and semiconductor properties of pure Ti were not significantlly 443 altered by low levels of alloying with Sn and Cr, only by using the IMPS technique - and 444 employing a model with a sufficient number of parameters, including recombination rate, $\mathrm{k}_{2}$, 445 reaction rate of interest, $\mathrm{k}_{1}$, and space-charge capacitance, $\mathrm{C}_{\mathrm{S}}$ - was the mechanism for the 446 catalytic behavior of the alloying elements adequately captured to permit comparison with 447 theoretical predictions. (1) (1) . .

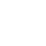


2

3

\section{Acknowledgments}

6451 This work was sponsored by the Office of Naval Research, ONR, under grant/contract number

8452 N0001415WX00948; the views and conclusions contained herein are those of the authors and

๑ 453 should not be interpreted as necessarily representing the official policies or endorsements, either 


\section{References}

[1] D.A. Jones, Principles and prevention of corrosion, 2nd ed., Prentice Hall, Englewood Cliffs, NJ, 1996.

[2] F.P. Mansfield, E. P. , Galvanic corrosion of bare and coated Al alloys coupled to stainless steel 304 or Ti-6Al-4V, Corrosion Science, 71 (1973) 605-621.

[3] X.L. Zhou, C.;Hashimoto,T.;Hughes,A.E.;Thompson,G.E., Study of localized corrosion in AA2024 aluminium alloy using electron tomography, Corrosion Science, 58 (2012) 299-306.

[4] W.L. Zhang, G.S. Frankel, Transitions between pitting and intergranular corrosion in AA2024, Electrochimica Acta, 48 (2003) 1193-1210.

[5] C.H. Hamann, Hamnett, A., Vielstich, W., Electrochemistry, Wiley-VCH, Weinheim, 1998.

[6] W. Vielstich, A. Lamm, H.A. Gasteiger, Handbook of fuel cells : fundamentals, technology, and applications, Wiley, Chichester, England ; New York, 2003.

[7] X.M. Ge, A. Sumboja, D. Wuu, T. An, B. Li, F.W.T. Goh, T.S.A. Hor, Y. Zong, Z.L. Liu, Oxygen Reduction in Alkaline Media: From Mechanisms to Recent Advances of Catalysts, Acs Catal, 5 (2015) 4643-4667.

[8] I.C. Man, H.Y. Su, F. Calle-Vallejo, H.A. Hansen, J.I. Martinez, N.G. Inoglu, J. Kitchin, T.F. Jaramillo, J.K. Norskov, J. Rossmeisl, Universality in oxygen evolution electrocatalysis on oxide surfaces, ChemCatChem, 3 (2011) 1159-1165.

[9] S.A. Policastro, C.M. Hangarter, D.J. Horton, J.A. Wollmershauser, D.F. Roeper, Effect of Low-Concentration Alloying in Titanium on Reduction Reaction Kinetics in Alkaline Environments, J Electrochem Soc, 163 (2016) C269-C274.

[10] L.M. Peter, Dynamic aspectgs of semiconductor photoelectrochemistry, Chemical Reviews, 90 (1990) 753-769.

[11] L.G. Austin, H. Lerner, Review of fundamental investigations of silver oxide electrodes, United States Army Materiel Commande, Washington, DC, 1965.

[12] D.M. Tench, E. Yeager, Capacitance Measurements on Lithiated Nickel-Oxide Electrodes, J Electrochem Soc, 120 (1973) 164-171.

[13] G.A. Zhang, Y.F. Cheng, Micro-electrochemical characterization and Mott-Schottky analysis of corrosion of welded X70 pipeline steel in carbonate/bicarbonate solution, Electrochimica Acta, 55 (2009) 316-324.

[14] J.D. Kim, S.I. Pyun, M. Seo, Effect of hydrogen on stresses in anodic oxide film on titanium, Electrochimica Acta, 48 (2003) 1123-1130.

[15] J.R. Birch, T.D. Burleigh, Oxides formed on titanium by polishing, etching, anodizing, or thermal oxidizing, Corrosion, 56 (2000) 1233-1241.

[16] J.W. Halley, M. Kozlowski, M. Michalewicz, W. Smyrl, N. Tit, Photoelectrochemical Spectroscopy Studies of Titanium-Dioxide Surfaces - Theory and Experiment, Surface Science, 256 (1991) 397-408.

[17] K. Rajeshwar, Charge-Transfer in Photo-Electrochemical Devices Via Interface States Unified Model and Comparison with Experimental-Data, J Electrochem Soc, 129 (1982) 10031008.

[18] J. Schneider, M. Matsuoka, M. Takeuchi, J.L. Zhang, Y. Horiuchi, M. Anpo, D.W. Bahnemann, Understanding TiO2 Photocatalysis: Mechanisms and Materials, Chemical Reviews, 114 (2014) 9919-9986.

[19] M.E. Orazem, P. Shukla, M.A. Membrino, Extension of the measurement model approach for deconvolution of underlying distributions for impedance measurements, Electrochimica Acta, 47 (2002) 2027-2034. 
[20] G.J. Brug, A.L.G. Vandeneeden, M. Sluytersrehbach, J.H. Sluyters, The Analysis of Electrode Impedances Complicated by the Presence of a Constant Phase Element, J Electroanal Chem, 176 (1984) 275-295.

[21] F.L. Mantia, H. Habazaki, M. Santamaria, F. Di Quarto, A critical assessment of the MottSchottky analysis for the characterization of passive film-electrolyte junctions, Russian Journal of Electrochemistry, 11 (2010) 1306-1322.

[22] K. Azumi, T. Ohtsuka, N. Sato, Mott-Schottky plot of the passive film formed on iron in neutral borate and phosphate solution, Journal of the Electrochemical Society, 134 (1987) 13521357.

[23] V.V. Brus, A.K.K. Kyaw, P.D. Maryanchuk, J. Zhang, Quantifying interface states and bulk defects in high-efficiency solution-processed small-molecule solar cells by impedance and capacitance characteristics, Prog Photovoltaics, 23 (2015) 1526-1535.

[24] B. Hirschorn, M.E. Orazem, B. Tribollet, V. Vivier, I. Frateur, M. Musiani, Determination of effective capacitance and film thickness from constant-phase-element parameters, Electrochimica Acta, 55 (2010) 6218-6227.

[25] J.M. Bolts, M.S. Wrighton, Correlation of Photocurrent-Voltage Curves with Flat-Band Potential for Stable Photoelectrodes for the Photoelectrolysis of Water, Journal of Physical Chemistry, 80 (1976) 2641-2645.

[26] A. Goosens, Intensity-modulated photocurrent spectroscopy of thin anodic films on titanium, Surface Science, 365 (1996) 662-671.

[27] J.R. Birch, T.D. Burleigh, Oxides formed on titanium by polishing, etching, anodizing, or thermal oxidizing, Corrosion, 56 (2000) 1233-1241.

[28] A. Bianconi, S. Stizza, R. Bernardini, S. Nannarone, Electronic Structure of Ti2O3 from Single Crystal Thermoreflectance Spectroscopy, physica status solidi (b), 93 (1979) 767-774.

[29] Y. Ma, X. Wang, Y. Jia, X. Chen, H. Han, C. Li, Titanium dioxide-based nanomaterials for photocatalytic fuel generations, Chemical Reviews, 114 (2014) 9987-10043.

[30] S.G. Hickey, D.J. Riley, Intensity modulated photocurrent spectroscopy studies of CdS nanoparticle modified electrodes, Electrochimica Acta, 45 (2000) 3277-3282.

[31] E.A. Ponomarev, L.M. Peter, A generalized theory of intensity modulated photocurrent spectroscopy (IMPS), Journal of Electroanalytical Chemistry, 396 (1995) 219-226.

[32] R.H. Wilson, T. Sakata, T. Kawai, K. Hashimoto, Analysis of the Transient-Response of a Semiconductor-Electrolyte Circuit to a Short Light-Pulse - Application to Cdse Electrodes, J Electrochem Soc, 132 (1985) 1082-1087.

[33] E.A. Ponomarev, S.D. Babenko, Theoretical-Analysis of the Laser-Induced Phototransient Response of Semiconductor Electrolyte Circuits with Current-Doubling Reactions, J Electroanal Chem, 371 (1994) 27-35.

[34] J. Li, L.M. Peter, Surface recombination at semiconductor electrodes, Journal of Electroanalytical Chemistry and Interfacial Electrochemistry, 199 (1986) 1-26.

[35] L.M. Peter, Dynamic Aspects of Semiconductor Photoelectrochemistry, Chemical Reviews, 90 (1990) 753-769.

[36] J.J. Kelly, R. Memming, The Influence of Surface Recombination and Trapping on the Cathodic Photocurrent at P-Type Iii-V-Electrodes, J Electrochem Soc, 129 (1982) 730-738.

[37] J. Li, L.M. Peter, Surface recombination at semiconductor electrodes, Journal of Electroanalytical Chemistry and Interfacial Electrochemistry, 193 (1985) 27-47. 
[38] J. Suntivich, H.A. Gasteiger, N. Yabuuchi, H. Nakanishi, J.B. Goodenough, Y. Shao-Horn, Design principles for oxygen-reduction activity on perovskite oxide catalysts for fuel cells and

\section{8 metal-air batteries (vol 3, pg 546, 2011), Nat Chem, 3 (2011) 647-647.}

8549 [39] P. Liao, J.A. Keith, E.A. Carter, Water Oxidation on Pure and Doped Hematite (0001) Surfaces: Prediction of $\mathrm{Co}$ and $\mathrm{Ni}$ as Effective Dopants for Electrocatalysis, Journal of the American Chemical Society, 134 (2012) 13296-13309. 